\title{
CADUCIDAD DE LA COMUNICACIÓN DE SUBASTA EL TERCERO REGISTRAL CONFORME LA APLICACIÓN DE LOS PRINCIPIOS REGISTRALES ${ }^{1}$
}

\author{
EXPIRY OF AUCTION COMMUNICATION \\ THE THIRD REGISTRY ACCORDING TO THE APPLICATION OF THE REGISTRY \\ PRINCIPLES
}

Por Vanesa Natalia Descalzo ${ }^{(*)}$

\begin{abstract}
Resumen: Este trabajo efectúa un análisis de la caducidad de la comunicación de subasta, tanto desde el derecho sustantivo como desde el punto de vista procesal. Se analiza la buena fe de los terceros embargantes y los adquirentes, desde el estudio de la institución subasta, sus momentos, y el impacto de los principios registrales en la misma (principalmente buena fe y caducidad) para así poder comprender el alcance y finalidad de la comunicación de subasta.
\end{abstract}

Palabras Claves: Principios registrales - subasta - comunicación de subasta - inscripción caducidad registral

\begin{abstract}
This paper analyses the expiration of the auction communication, both from the substantive law and from the procedural point of view. The good faith of the third party foreigners and the acquirers is analyzed, from the study of the auction institution, its moments, and the impact of the registration principles on it (mainly good faith and expiration) in order to under stand the scope and purpose of auction communication.
\end{abstract}

Ketwords: Registration principles - auction - communication of auction - registration - expiry of registration

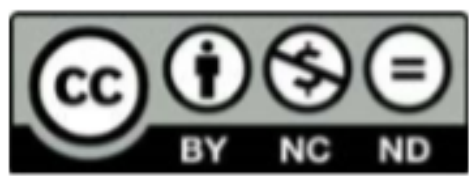

Artículo publicado bajo Licencia Creative Commons Atribución-No Comercial-Sin

Derivar. (C) Universidad Católica de Córdoba

DOI http://dx.doi.org/10.22529/adc.2019(13)03

\footnotetext{
${ }^{1}$ Artículo recibido el 17 de agosto de 2019 ya probado para su publicación el 2 de noviembre de 2019

(*) Abogada. Notaría. Auxiliar en Poder Judicial de la Pcia de Córdoba. Docente Universidad Siglo 21. Adscripta UNC. Maestrando en Derecho del trabajo y la seguridad social UNTREF. Miembro de la AADDTYSS. Autora de publicaciones científicas. Investigadora SECyT. mail: vanedescalzo@ hotmail.com
} 


\section{INTRODUCCIÓN}

En el sistema jurídico argentino, la adquisición de derechos reales se estructuró, en el Código Civil, sobre la teoría del título y modo receptando la publicidad registral únicamente para la hipoteca ya que la misma no se ejerce por la posesión. Con la evolución de nuestra regulación, la publicidad registral se extendió a todo derecho real, materializado con la sanción de la Ley 17.711 y Ley 17.801, que receptaron la publicidad para derechos reales sobre inmuebles con efecto declarativo. El sistema registral otorga seguridad al tráfico jurídico mediante la publicidad formal de las mutaciones reales por medio de certificados, informes y exhibición de libros. Las certificaciones expedidas por el Registro, a diferencia de los informes, resultan importantes por sus efectos, como una anotación preventiva en favor del solicitante, reserva de prioridad y bloqueo registral, con lo cual se protege la situación jurídica del adquirente para que no resulte menoscabado por gravámenes o afectaciones que pueden recaer sobre la cosa. A través de este mecanismo el documento celebrado en determinadas condiciones se considera presentado en una fecha anterior a la de su celebración, por el Principio de Prioridad Registral que constituye la aplicación del principio prior in tempore potior in iure (primero en el tiempo mejor en el derecho).

En materia de subastas el artículo 34 de la ley 5.771 de Córdoba prevé la expedición de un informe de anotación preventiva de subasta sujeta a un plazo de caducidad de 150 días, pero establece que la comunicación de subasta no estará sujeta a plazo de caducidad alguno. Así para evitar herir la seguridad jurídica y la buena fe de los terceros que se basan en la publicidad registral, el legislador articuló la posibilidad de adentrarse a la inscripción definitiva mediante la llamada comunicación de subasta, artículo 34, ley 5771, cuyo único propósito es justamente alertar o dar noticia a los terceros registrales sobre la mutación jurídica real producida y también tutelar el derecho del adquirente en la misma.

\section{FUNDAMENTACION DEL TEMA ELEGIDO.}

La falta de un plazo de caducidad de la comunicación de subasta, ha sido objeto de discusiones doctrinarias y jurisprudenciales, en cuanto si los acreedores embargantes posteriores a la venta judicial pero previos a la inscripción de la misma, deben ser o no 
considerados de buena fe. Lo expresado nos lleva a preguntarnos: ¿Pueden los acreedores del ejecutado trabar una medida cautelar sobre el bien subastado? En su caso ¿Pueden ser considerados de buena fe? ¿Quién debe prevalecer entre el adquirente en subasta y el tercero embargante? En virtud de lo expresado se plantea el problema a dilucidar si la comunicación de subasta, que se materializa con la expedición del certificado judicial, es publicidad suficiente para excluir o no, la buena fe del tercero embargante y como consecuencia de ello, si la anotación de la comunicación de subasta es susceptible de ser sometida a plazo de caducidad alguno.

\section{OBJETIVOS DEL TRABAJO.}

\section{GENERALES:}

- Determinar la situación jurídica del tercero registral que posterior a la comunicación de subasta anota una medida cautelar sobre el inmueble y a los fines de ejecutar un bien cuyo deudor es el titular registral.

\section{ESPECIFICOS:}

- Establecer si el instituto de la caducidad es susceptible de ser aplicado a la comunicación de subasta

- $\quad$ Conocer los alcances y la finalidad de la comunicación de subasta

- Conocer la interpretación que la doctrina y la jurisprudencia le dan a la comunicación de subasta

- Interpretar los efectos de la comunicación de subasta a la luz del análisis de los principios registrales

Para ello desarrollaremos en primer lugar, nociones generales relativas al concepto de subasta, luego la regulación de la comunicación de subasta y sus efectos jurídicos, los principios que atraviesan esta situación registral como también las conductas de las partes intervinientes en el fenómeno en estudio, para finalizar con el análisis puntual de la posible caducidad de dicha comunicación. 


\section{SUBASTA. NOCIONES.}

Podemos concebir a la subasta judicial como el acto a través del cual se produce la realización forzada de los bienes del deudor. La importancia de esta figura radica en que, en gran cantidad de casos, el acreedor solo verá satisfechas sus pretensiones una vez finalizado dicho acto con el producido de los bienes. Hoy se considera que "el derecho a la tutela judicial efectiva comprende también el derecho a que el fallo judicial se cumpla", por lo que es la subasta lo que en la práctica va a permitir que se materialice la condena, haciendo operativa a la sentencia.

La subasta es un instituto que estaba regulado en el Código velezano como un supuesto de venta forzosa en el art. 1324, inc. 43; mientras que en el Código Civil y Comercial, podemos encontrar su correlación en el art. 1128, que sienta la misma base, "Obligación de vender. Nadie está obligado a vender, excepto que se encuentre sometido a la necesidad jurídica de hacerlo. " Pero omite la enumeración de las diferentes situaciones contempladas en el antiguo art. 1324.

La denominación "subasta", conforme explica Lino Palacio (1969), proviene de la expresión latina "sub hasta": venta bajo la lanza. Ello por cuanto en Roma los bienes integrantes del botín de guerra tomado a los enemigos se vendían públicamente clavándose en el lugar en que se realizaría el acto una asta como símbolo del Estado y a efectos de garantizar las operaciones realizadas.

Actualmente, a través de este acto se produce la transformación de los bienes pertenecientes al deudor (ejecutado) en una suma de dinero, destinada a solventar el crédito del acreedor (ejecutante). Así se ha dicho que la subasta pública es el acto procesal mediante el cual se enajena, por un auxiliar del juez que actúa en su representación, el bien o los bienes embargados para satisfacer con su producido el importe del crédito que dio origen a la ejecución.

\footnotetext{
2 Tribunal Constitucional de España, Sala 1º, Sent. No 49, 30/03/2004. Recurso de amparo 4791-2001. Promovido por Nationale Nederlanden Vida Compañía de Seguros y Reaseguros, S.A.E., frente a un Auto de la Audiencia Provincial de Murcia en ejecución de Sentencia en causa por delitos de estafa y falsedad. ${ }^{3}$ Código Civil, Art 1324 inc. 4): “...Nadie puede ser obligado a vender sino cuando se encuentre sometido a una necesidad jurídica de hacerla, la cual tiene lugar en los siguientes casos: ... 4) cuando los bienes del propietario de la cosa hubieren sido rematados en virtud de ejecución judicial..." ${ }^{4}$ Código Civil y Comercial, Ley 26944, art 1128
} 


\section{MOMENTOS. ITER INSCRITORIO.}

En la Provincia de Córdoba, la regulación del proceso de subasta y la adquisición de bienes por dicho medio, en lo que hace a sus aspectos registrales, encuentra su regulación legal en el juego que se genera entre las normas provinciales $5771^{5}$ (Registro General de la Provincia) y $7191^{6}$ (Ley de Martilleros y Corredores Públicos), las resoluciones que dicta el Registro General de la Propiedad de la Provincia, y la ley nacional 17801(Régimen De Los Registros De La Propiedad Inmueble De Las Provincias, Capital Federal, Territorio Nacional De Tierra Del Fuego, Antártida E Islas Del Atlántico Sur.), donde se receptan los principios generales del sistema registral.

Dentro de ese plexo normativo, la doctrina distingue tres etapas en la adquisición de bienes por subasta, en lo que se refiere al registro de la misma (con la posibilidad de que en forma previa, como nos encontramos en un proceso de ejecución de sentencia, haya un embargo solicitado en el marco del proceso en cuestión): 1) La anotación preventiva de subasta; 2) La comunicación de subasta; 3) La inscripción definitiva del bien a nombre del adquirente. (VENTURA, 2007)

Esto se debe a que, a diferencia de lo que sucede en el ámbito notarial en que, por imperio del denominado Principio de Unidad de Acto, todo sucede en un mismo momento, en materia judicial el título se va gestando en diferentes instancias. La primer etapa (art. 23 de la ley 17801 y art. 34 de la ley provincial 5771), implica que antes de proceder con la subasta judicial de inmuebles (cuyo fin es la transmisión forzosa de los mismos), el funcionario público debe requerir la certificación expedida a tal efecto por el Registro, en la que se consigna el estado jurídico de los bienes y de las personas según las constancias registradas, que en nuestra Provincia se expiden practicando anotaciones preventivas en el folio respectivo del acto jurídico dispuesto por la autoridad competente.

Ese verdadero certificado (a pesar de la denominación de informe que tiene en la ley local), es lo que se denomina "informe judicial con anotación preventiva de subasta”, no sólo da noticia respecto de la situación jurídica del bien y de sus titulares, sino que genera dos

\footnotetext{
${ }^{5}$ Ley Provincial 5771. B.O. 12.11.74

${ }^{6}$ Ley Provincial 7191 B.O. 19.11.84

${ }^{7}$ Ley Nacional 17801 B.O. 28.06.68
} 
consecuencias claves en salvaguarda de la denominada seguridad estática o preeminencia del adquirente y su derecho subjetivo: el bloqueo registral y la reserva de prioridad. El bloqueo registral impide cualquier modificación de la situación jurídica del inmueble, mientras que la reserva de prioridad produce efectos de anotación preventiva a favor de quién requiera la inscripción del documento para cuyo otorgamiento se hubiera solicitado. Según Fuster (2008), la reserva de prioridad "es una figura jurídico-registral que consiste en asegurar una determinada colocación registral, en el encadenamiento de las titularidades registrales sucesivas (tracto sucesivo -art. 15, ley 17.801-), a un documento con vocación inscriptoria". Cabe destacar, que dicho bloqueo y reserva tienen un plazo de vigencia por el término de 150 días, dentro de los cuales se deben realizar todos los actos y diligencias necesarias a los fines de realizar la subasta correspondiente, y así conservar los efectos mencionados.

La segunda etapa en eso que se denomina "camino o iterinscriptorio", es la comunicación de subasta. La subasta, debe haberse realizado dentro del plazo de ciento cincuenta (150) días, a los fines de que no caduque la anotación preventiva. Luego, y conforme lo establece el art. 58 de la Ley de Martilleros y Corredores públicos (7191): "Cuando se hayan subastado bienes registrables, es obligación del martillero y del actuario, notificar al órgano registral la realización del acto dentro de los cinco días."

Debido a que "la naturaleza particularmente compleja de los títulos de adquisición por subasta impide en ciertas situaciones que su instrumentador logre todos los elementos para posibilitar la registración inmediata de la mutación jurídico real producida", se regula la comunicación de subasta en el art. 34 de la ley 5771 a los fines de anoticiar a los terceros registrales sobre la nueva situación jurídica del bien, y de proteger al adquirente en el proceso de subasta. Según el art. 28.1 de la Resolución General No 4/2015, actualmente la comunicación de subasta no está sujeta a plazo de caducidad, adecuándose a la ley provincial 5771, en donde dicho instituto jurídico está regulado sin plazo.

\section{LOS PRINCIPIOS REGISTRALES Y LA SUBASTA.}


Previo al análisis minucioso de la figura de la comunicación de subasta, cabe aclarar que entramos en un ámbito donde adquieren relevancia tres principios registrales: publicidad, inscripción y prioridad.

Al ser los derechos reales de carácter absoluto (oponibles erga omnes), se genera la necesidad de que haya algún mecanismo que permita dar publicidad a aquellos actos que constituyan, modifiquen o extingan los mismos. Así, cualquier miembro de una comunidad puede hacer cumplir el deber jurídico de respetar el derecho real en cuestión, y con mayor relevancia aún, permitir la tutela de aquellos terceros que poseen un interés legítimo para oponerse a la invocación de derechos que no pudieron conocer. Dispone el art. 21 de la ley 17.801 en su primera parte que "El Registro es público para el que tenga interés legítimo en averiguar el estado jurídico de los bienes, documentos, limitaciones o interdicciones inscriptas." Se entiende que la adopción del sistema registral permite darle la mayor plenitud al principio de publicidad.

Por otro lado, el principio de inscripción o registración implica la toma de razón por parte del registro, de un hecho o acto jurídico que constituya, transmita, modifique o extinga un derecho real. En nuestro ordenamiento, la inscripción es obligatoria en el caso de bienes inmuebles, teniendo efectos declarativos. El derecho real nace fuera del Registro, pero debe inscribirse a los fines de publicidad y oponibilidad a terceros.

Por último, el ius preferendi (además de conferir privilegios sobre el bien que se trata) indica que quien es primero en el tiempo, es mejor en el derecho, es decir que goza de una prioridad.(KIPER 2016) El principio de prioridad implica la adjudicación automática de preferencia en los derechos reales, especialmente en los que recaen sobre inmuebles, para quien registre el derecho en primer término, o logre obtener la inscripción de medidas cautelares en su favor o reserve mediante certificado la celebración de un negocio, sobre el que adquiera un derecho o posición registral con posterioridad. El fin de este principio es evitar contradicciones entre los asientos registrables, y así brindar seguridad jurídica. Pero, si partimos de la idea de que esta última está compuesta por dos aspectos, seguridad jurídica dinámica y estática; si bien complementarios, en el caso particular de la comunicación de subasta y la cuestión de su plazo de caducidad, se plantea un dilema respecto de cuál es valor que deseamos proteger. 
La cuestión de la caducidad de la comunicación de subasta generaba una serie de problemas en las relaciones jurídicas y el tráfico de bienes ante la situación del adquirente en subasta que no completa el trámite de inscripción en el Registro y estaba expuesto a que los acreedores del ejecutado y aún titular registral, traben medidas cautelares sobre el bien subastado, por lo que si se vencía el plazo de comunicación de subasta, había que determinar quién prevalecía en tal circunstancia; si el adquirente o el tercero embargante, particularmente en aquellos casos donde quién adquiría el bien ya había entrado en posesión del mismo. Podemos decir que el conflicto radica en determinar quién tiene preeminencia; si el adquirente en subasta (asegurando la seguridad estática o del derecho subjetivo) o el tercero embargante (protegiendo la seguridad dinámica al evitar que el bien sea sustraído del tráfico jurídico).

\section{EL PRINCIPIO DE BUENA FE}

Desarrollaremos en esta oportunidad un concepto que nutre y atraviesa no solo las relaciones jurídicas sino también el ejercicio de los derechos; personales y reales. Estamos hablando de la buena fe, la cual el CCyC ha definido en su parte general en el art. 9 al decir que "los derechos deben ser ejercidos de buena fe" y es de observar y resaltar que al ser incorporado en la parte general del Código, se considera un principio que nutre todo el sistema jurídico, lo que supone que su influencia se proyecte a todas las relaciones jurídicas de derecho privado, no resultando necesario que una norma específica lo determine para un supuesto en particular, sino que se encuentra contemplado en este artículo.

La buena fe puede ser concebida en su faz objetiva y subjetiva. Podemos decir que la buena fe objetiva tiene relación con el comportamiento correcto, leal, que se refiere al momento de formación y celebración de los actos jurídicos; en cambio la buena fe subjetiva hace referencia a la protección de una creencia o certeza razonable, a decir de Alterini (2015):"sea cuando se confía en la titularidad del propio derecho o interés, sea cuando se confía en la titularidad del ajeno, lo cual parte de la idea de que las personas pueden confiar en las situaciones tal como se presentan”.

Pero porque es importante hablar de la buena fe en el análisis de la comunicación de subasta? Porque surgen cuestiones que ameritan su desarrollo cuando tenemos un tercero 
embargante de un inmueble que comunicada su subasta no se inscribió de manera definitiva. Aquí debemos analizar la buena fe en sus diferentes dinámicas, para determinar si ese tercero tiene derecho sobre el inmueble subastado o le es oponible dicha comunicación aunque la inscripción definitiva no haya sido realizada.

Se puede decir que conforme el contenido del principio de buena fe del art. 9 CCyC, la tutela solamente abarca los casos de un sujeto cauteloso y previsor que haya efectuado las diligencias necesarias para cerciorarse de la legitimidad de su adquisición. La doctrina, a los fines de considerar cuando existe realmente buena fe combina las dos corrientes (ARRIOLA 2011). Se considera que el tercero ha obrado correctamente cuando la buena fe se deja traslucir en su conducta diligente, así lo ha reconocido la doctrina diciendo.

\begin{abstract}
"(...) ...he criticado la postura de aquellos que ven en la inscripción registral un tercer requisito para la adquisición de un derecho real, que se sumaría al título y al modo. He sostenido, y sigo sosteniendo enfáticamente, que el derecho real se adquiere "extrarregistralmente", con sólo título y modo, y la inscripción sólo tiene por fin la "seguridad del tráfico", protegiendo a terceros "interesados", que en razón de su vinculación jurídica con alguna de las partes en la transmisión, podrán actuar apoyándose en el Registro, "como si no hubiese transmisión", si no tuvo publicidad registral... Ya la doctrina ha precisado suficientemente el concepto de tercero registra, no obstante lo cual podemos -en resumidas palabras- expresar que es aquél que obrando de buena fe ha obtenido -en palabras de Ventura- "colocación registral"(VENTURA 2005)
\end{abstract}

Es a este tercero (al tercero registral) y no a la comunidad toda (carácter erga omnes) al que la registración publicita y hace oponible el acto objeto de registración. Ello, toda vez que lo dicho implicaría desmerecer el sistema jurídico publicitario registral de carácter declarativo que impera en materia inmobiliaria (calidad reconocida por la doctrina mayoritaria: Bustamante Alsina, Lavigne y Gomez, Perez Lasala, Adrogue, Alsina Atienza, Moisset De Espanes, -Entre Otros-(FUSTER 2008).

Y -además- en palabras del Dr. Fuster, haría de la registración un requisito cuasi constitutivo de los derechos reales, en la inteligencia de que el carácter de erga omnes es esencial y consustancial a los mismos. 
En materia judicial y más precisamente de subasta, el acto de remate implica o marca el momento en el que comienza a nacer o gestarse el título de adquisición, en cambio, en materia judicial el título se va gestando en diferentes instancias (FUSTER 2008). En ese proceso, se comienza con el acto de remate, le continua su anoticiamiento al registro (comunicación de subasta) y concluye con la inscripción registral definitiva; considerando que la finalidad de esta comunicación tiene por fin inmediato evitar casos de "doble subasta" por lo cual ponen en conocimiento de parte interesada que se realizó dicha subasta y para el caso de medidas cautelares, que dicho inmueble fue subastado y desde ese momento deberá investigar si se ha realizado el acto de remate con éxito por lo que el bien pertenece a su adquirente o cual es la situación en la que se encuentra respecto a su titularidad. Se protege cualquier mutación real que pudiera pretender un tercero en el tiempo que media (generalmente demasiado extenso) entre el acto de remate y la inscripción definitiva del bien inmueble en cuestión.

Esta circunstancia ha sido expresamente reconocida por fallos, en el cual dejan sentado que: "(...) Para que la venta efectuada en subasta judicial pueda ser opuesta a terceros, la orden de subasta debe comunicarse al Registro de la Propiedad a fin de que éste efectúe la "preanotación" pertinente. De no tomarse ese recaudo la transmisión no podrá oponerse al embargante posterior, respecto del cual rige plenamente el sistema de publicidad ideado por la ley 17.801. La inscripción que el comprador en remate efectúe con posterioridad a la anotación del embargo, no eximirá al titular de las consecuencias de la medida adoptada. (...)" (la bastardilla nos pertenece). ${ }^{8}$

Así las cosas, podemos compartir con doctrina mas que respetada en el tema que adjudicarle caducidad a la comunicación de subasta implica "premiar la mala fe" de quien pretende prevalerse de la "supuesta" falta de vigencia de un asiento registral -en franca violación de la normativa de fondo- para adquirir un bien "ya vendido" (por subasta) (FUSTER 2008)

Si tenemos presente que el concepto actual de la buena fe consagrada en el CCyC, el cual atraviesa el ejercicio de los derechos en todos los aspectos de la vida humana, mal

\footnotetext{
${ }^{8}$ Cámara Civil y Comercial Mar del Plata, Sala 2, 04/02/2003, "Longo, Walter M. s./ Tercería de Dominio en autos Collia v. Fucci s./ Ejecución de Alquileres".
}

\begin{tabular}{llcl}
\hline \hline ANUARIO DE DERECHO CIVIL & TOMO XIII & 2019 & Página 111
\end{tabular}


podríamos decir que habiendo cumplimentado con la publicidad registral, el tercero embargante no conoce la situación en la que se encuentra el inmueble; mucho menos aun si nos enrolamos en la teoría del negocio en gestión, donde consideramos su plena aplicación en el caso ya que de no haber mutado la situación jurídica del bien, dicha comunicación al menos obliga a quien pretende ingresar una medida cautelar sobre dicho bien, tomar las medidas diligentes necesarias que derivan de dicha anotación judicial para averiguar en autos cual ha sido el real destino de dicho inmueble, no pudiendo invocar buena fe cuando fue de conocimiento cierto por medio de asientos registrales que la subasta se había producido.

\section{COMUNICACIÓN DE SUBASTA. CONCEPTO.}

En materia de subasta, la teoría del "título en gestación" conlleva que el título se configura en distintas instancias temporales comenzando con el remate hasta la inscripción registral definitiva del bien a nombre del comprador. Así, el "iterinscriptorio" de la subasta, tal como lo describiéramos en apartados anteriores se encuentra conformado por cuatro etapas: embargo previo del acreedor sobre el bien a subastar, anotación preventiva de subasta, comunicación de subasta e inscripción del bien a nombre del adquirente.

Ahora bien, en relación al tema que nos ocupa, cabe señalar que el tercer momento aludido (comunicación de subasta) consiste en anoticiar al Registro General de la Provincia que se ha realizado una subasta y se ha adjudicado el bien subastado a un adquirente determinado, aunque no conste que se le haya hecho entrega de la posesión o pagado el precio. En una palabra, este instituto se utiliza para dar a conocer a terceros la mutación jurídica real que se ha efectuado. Así, se ha sostenido:

"Desde que se genera una mutación jurídico-real hasta que llega a tener su reflejo registral pasa un tiempo más o menos prolongado, según la eficiencia de los operadores judiciales (juez, martillero, etc.) y la calidad del servicio registral. De ahí que para anoticiar lo antes posible a la comunidad respecto de la citada mutación se utilice la llamada "comunicación de subasta", que constituye el adelanto de una situación que ya se ha producido (...) Esta comunicación de subasta es un anoticiamiento que sólo puede confundirse con la anotación provisoria, en cuanto a que la misma no cuenta con un título incontestable, puesto que puede aún ser impugnado; pero de ninguna manera participa de las características de una anotación provisoria”(VENTURA 2017) 
A más de ello, nótese que en el mismo trabajo se ha explicado:

\begin{abstract}
"en esta etapa el título de la subasta ya se ha producido cuando el asiento lo pregona; falta "aguardar su firmeza", pero ya conocemos a ciencia cierta que hubo subasta. En tales casos ni siquiera es menester acudir al expediente, como dice la norma y como se lo exigiremos a quien sólo advierta una simple anotación preventiva, cuyo destino aún no sabemos si determinó o no la subasta para la que se solicitó"(VENTURA 2017)
\end{abstract}

En efecto, y conforme lo señalado precedentemente, la comunicación de subasta es un acto jurídico registral que persigue dar a conocer a los terceros la realización de una subasta, teniendo en miras una finalidad preventiva. No obstante ello, de ningún modo podemos afirmar que el acto jurídico aludido se encuentra sujeto a plazo de caducidad alguno.

\title{
FINALIDAD DE LA COMUNICACIÓN DE SUBASTA
}

En este punto es menester señalar que el instituto -objeto de estudio del presente trabajotiene como fin anoticiar el desplazamiento ocurrido para poder evitar la producción de la "doble subasta" de un bien inmueble y el ingreso de medidas cautelares entre el tiempo que transcurre entre la realización de la subasta y la inscripción definitiva a nombre del adquirente. Siguiendo esta línea de pensamiento, la Resolución General Número Uno (1) del Registro General de la Provincia, de fecha veinticinco de junio de dos mil ocho recalca en su considerando 2 :

"Que para evitar herir la seguridad jurídica y la buena fe de los terceros que se basen en la publicidad registral, el legislador articuló la posibilidad de adelantarse a la inscripción definitiva mediante la llamada 'comunicación de subasta', art. 34 de la ley 5771, cuyo único propósito es justamente alertar o dar noticia a los terceros registrales sobre la mutación jurídico real producida y también tutelar el derecho del adquirente en la misma" (MOISSET DE ESPANES- FUSTER, 2009).

En definitiva, con la comunicación de subasta se persigue hacer saber que la inscripción depende de la decisión de un juez, lo que implica que el asiento no caduca y debe esperarse la resolución del tribunal. En una palabra, si se suprimiera la etapa de comunicación de subasta podrían acontecer numerosas situaciones problemáticas. Ello, por cuanto podrían ingresar al registro medidas cautelares que tendrían prioridad respecto de la inscripción definitiva o bien podría producirse la doble disposición del bien inmueble. Por ello, se ha 
entendido que adjudicarle caducidad a la comunicación de subasta implica desconocer la normativa de fondo que rige la cuestión y supone soslayar la finalidad y efectos prácticos del instituto e implica "premiar" la mala fe de quien pretende prevalerse de la "supuesta" falta de vigencia de un asiento registral para adquirir un bien ya vendido por subasta (FUSTER 2008).

\section{CADUCIDAD DE LA ANOTACION DE SUBASTA.}

La ley provincial 5.771 viene a completar el vacío legal existente en la ley nacional 17.801 en cuanto a la publicidad registral de las subastas, disponiendo en su art 34 en su segundo y tercer párrafo que:

"Los informes registrales para las transmisiones forzosas de derechos reales, se expedirán practicando anotaciones preventivas en el folio respectivo del acto jurídico dispuesto por la autoridad competente. En caso de subasta la anotación preventiva caducará de pleno derecho a los ciento cincuenta (150) días, corridos salvo que antes de ese plazo el Tribunal comunique al Registro la celebración del remate. Si el acto de subasta fuera observado, el Tribunal deberá comunicar al Registro de la resolución definitiva que recaiga en la incidencia."

Comenzando con el análisis del citado artículo, se advierte un primer error al utilizar el término de "Informe Registral", el cual debería reemplazarse por el de "Certificado Registral", lo cual es muy bien criticado por el Dr. Fuster al expresar: "La denominación de informe con anotación preventiva para subasta es totalmente incorrecta, toda vez que, el pretendido informe, es en realidad un verdadero certificado registral (judicial, en este caso) o certificado de ley, con sus consiguientes efectos jurídicos: la reserva de prioridad y el consecuente bloqueo registral.(FUSTER)"

A continuación el art. 34 señala que para el trámite del proceso de subasta, la ley acuerda una inscripción provisoria por 150 días, a dicho plazo se lo debe computar como días corridos y está sujeto a una caducidad de pleno derecho. Es importante destacar, como ya antes se ha mencionado, que esta anotación provisoria trae aparejada como consecuencia la reserva de prioridad y bloqueo registral durante ese término.

"De esta manera una vez que se ha procedido a su expedición, durante ciento cincuenta días el dominio queda bloqueado, asegurando la realización de la subasta libre de todo otra gravamen y 
garantizando, a pleno, el cobro del crédito por el ejecutante y solicitante de la citada anotación."(VENTURA 2017)

De este modo el art. 34 establece un plazo de caducidad para la llamada "anotación preventiva de subasta", el cual se aplica de pleno derecho a los ciento cincuenta días, teniendo el legislador al establecer este plazo una especial consideración en "que los tiempos judiciales tienen características especiales que superan la voluntad e incluso el accionar diligente de las partes". (MOISSET DE ESPANES, 2007)

Ahora bien, es necesario diferenciar la "anotación preventiva de subasta" que esta efectivamente sometida a un plazo de caducidad, de la "comunicación de subasta realizada" donde por aplicación analógica de lo dispuesto por la última parte del inciso b del artículo 9 de la ley 17.801, la notación o inscripción provisional se mantendrá vigente durante toda la sustanciación del problema que ha quedado sometido a resolución judicial (MOISSET DE ESPANES, 2007)

Art.9: ..."Cuando la decisión no fuese rectificada podrá promoverse el recurso o impugnación que correspondiere según la ley local, durante cuya sustanciación se mantendrá vigente la inscripción o anotación provisional...”

Por lo que a partir de la comunicación de subasta ya no hay plazo de caducidad, y ese asiento conservará su validez y efectos mientras se substancie el trámite judicial. Es decir, que la vigencia de este asiento está supeditada a la duración que tenga el expediente de aprobación del remate. ${ }^{9}$

Todo lo cual es acorde a lo dispuesto por el Artículo 342 del C.P.C.C. que en su inciso primero prescribe: “No se producirá la perención: 1) En el procedimiento de ejecución de sentencia, salvo en los incidentes...", es decir que en los procedimientos de ejecución de sentencia no cabe la perención, y ello se basa en el hecho que la jurisdicción ya se ha pronunciado.

\footnotetext{
${ }^{9}$ Cámara Civil y Comercial de $4^{\circ}$ Nominación, 25 de febrero de 2008, en autos: "Sahade Silvana Andrea c/ Milotich Hector y otros - Declarativo .- Tercería de Dominio - Dominio de Tarif Ramon Amin - Yaz de Azize"
} 
Según Díaz Villasuso (2016), uno de los fundamentos en los cuales descansa el instituto de la perención reside en el incumplimiento de la carga de impulso que el principio dispositivo pone en cabeza de las partes. Pero, tal carga procesal admite excepciones y el ordenamiento adjetivo establece que en determinados procedimientos como es el caso de la ejecución de una sentencia firme inc. 1 art 342 C.P.C.C. no se produce caducidad, de suerte que las demoras o inactividades que sobrevengan durante su transcurso no son idóneas para desencadenar su extinción. "Con el dictado de la sentencia que pone fin al proceso, ha finalizado la etapa cognoscitiva del mismo, quedando entonces pendiente su eventual ejecución, respecto de la cual no pueden jugar los mismos factores que fundamentan la institución de la perención de instancia, ahora se trata de cumplimentar un mandato judicial"

Es decir, que para el caso particular del procedimiento de cumplimiento de la sentencia de remate recaída en juicio ejecutivo, no se aplica el instituto de la caducidad de instancia.

Por otra parte, el artículo 37 de la ley 17.801, que regula las caducidades que operan de pleno derecho no contempla el supuesto de la comunicación de subasta realizada. "Art.37: Caducan de pleno derecho y sin necesidad de solicitud alguna, por el transcurso del tiempo que expresa este artículo o por el que, en su caso, establezcan leyes especiales: a) La inscripción de la hipoteca, al vencimiento del plazo legal si antes no se renovare; b) Las anotaciones a que se refiere el inciso b) del artículo 2, a los cinco años, salvo disposición en contrario de las leyes. Los plazos se cuentan a partir de la toma de razón."

Art.2: “...b) Los que dispongan embargos, inhibiciones y demás providencias cautelares..."

Es decir que en la 17.801 solamente se contemplan como supuestos de caducidad de pleno derecho a las inscripciones de la hipoteca y a las mencionadas en el Art. 2 inc. b. (embargos, inhibiciones y demás providencias cautelares). Por lo cual, al entender que la naturaleza de la comunicación de subasta realizada no es la de una providencia cautelar, la misma queda fuera de los supuestos contemplados en la ley.

Asimismo si tenemos en cuenta que los plazos de caducidad deben estar fijados expresamente por la ley, y no pueden ser creados por la voluntad de un embargante, ni por 
las autoridades administrativas del Registro, y ni siquiera por los magistrados. ${ }^{10}$ No cabría posibilidad alguna de contemplar la caducidad de la anotación de comunicación de subasta producida, salvo el plazo de prescripción de diez años, previsto por la legislación común. Cuando el trámite finaliza con el auto de aprobación de la subasta, y esa resolución se encuentra firme e inatacable, el adquirente tiene un plazo para peticionar su inscripción en el Registro de diez años, o sea: la "actio res iudicata", que no prescribe hasta los 10 años de la resolución, y no se trata de un plazo de caducidad, sino de prescripción.

\section{CONCLUSIONES}

Como pudimos ver en el desarrollo del presente, hablar del instituto de la caducidad de la comunicación de subasta, amerita el desarrollo de diferentes temas que lo complementan.

Podemos comenzar diciendo que conforme nuestro ordenamiento jurídico, no es posible hablar de la caducidad de dicha comunicación, ya que fundados en los diferentes instrumentos legales que hemos desarrollado, no es posible aplicar aun analógicamente la figura de la caducidad. Asimismo, tal como mencionamos supra, si tenemos en cuenta el amplio concepto vigente en materia de buena fe, mal podríamos otorgar un mayor derecho a aquel tercero que teniendo conocimiento de un "negocio en gestión" el cual es publicitado mediante la comunicación de subasta, pretende hacer valer un derecho real sobre aquel adquirente.

En este caso, debería exigirse a este tercero la toma de recaudos previos tendientes a conocer de manera efectiva y actual cual es la situación jurídica de ese bien, mediante el acceso al expediente judicial y en su caso incitar al órgano jurisdiccional a la inscripción definitiva.

Aquí es donde consideramos radica el quid de la cuestión, ya que si bien entendemos que atenta contra la seguridad jurídica dinámica de los bienes la falta de inscripción, ya que estaría sustrayendo del trafico jurídico a un bien por un lapso de tiempo indeterminado; no podemos dejar de tener presente que la comunicación de subasta, fundados en el principio

${ }^{10}$ Cámara Civil y Comercial de $4^{\circ}$ Nominación, 25 de febrero de 2008, en autos : "Sahade Silvana Andrea c/ Milotich Hector y otros - Declarativo .- Tercería de Dominio - Dominio de Tarif Ramon Amin - Yaz de Azize" 
de publicidad y fe registral está poniendo en conocimiento de los terceros interesados, que dicho bien fue sometido a una ejecución forzada judicial y ya fue realizado, quedando pendiente la inscripción definitiva la cual terminara de perfeccionar el traslado del dominio sobre dicho inmueble, al dejar asentado en los registros el efectivo traspaso de titularidad registral. Por ello, compartimos que adjudicarle caducidad a la comunicación de subasta implica desconocer la normativa de fondo que rige la cuestión y supone soslayar la finalidad y efectos prácticos del instituto e implica "premiar" la mala fe de quien pretende prevalerse de la "supuesta" falta de vigencia de un asiento registral para adquirir un bien ya vendido por subasta.

Más aún si tenemos presente que el principio de publicidad registral tiene como finalidad generar oponibilidad frente a terceros, prioridad temporal en los asientos y sobretodo en relación al tema que analizamos, prevención del negocio en gestión; por lo que la anotación de dicha comunicación de subasta, en cumplimiento del principio de publicidad registral debe advertir al tercero interesado que tenemos un negocio en gestión (subasta judicial) que se encuentra en curso, afectando así la situación jurídica del inmueble.

\section{REFERENCIAS BIBLIOGRAFICAS}

\section{DOCTRINA}

ADROGUE, Manuel I. en "El tercero registral" — en Temas de Derechos Reales — Editorial Plus Ultra — Buenos Aires, 1979

ALTERINI Jorge H. Código Civil y Comercial Comentado. Editorial La Ley. 2015

ARRIOLA, Carolina; en "El tercero del artículo 1051 del Código Civil y la nulidad de subasta" - en Intervención de terceros y tercerías. Doctrina y jurisprudencia - . Ed. Advocatus, 2011

DIAZ VIllasuso Mariano A., Código Procesal Civil y Comercial de la Provincia de Córdoba, T.II Editorial Advocatus. 2016.

FUSTER, Gabriel Aníbal. Estudios sobre la subasta judicial. La Ley. Cita Online:0003/70036770-1. 
FUSTER, Gabriel Aníbal. Aspectos registrales de la subasta judicial. Cita Online:0003/70055757-1

FUSTER, Gabriel Aníbal. La "pretendida" caducidad de la comunicación de subasta. LLC2008 (febrero), 15. Cita Online:AR/DOC/322/2008.

KIPER, Claudio, Manual De Derechos Reales, Rubinzal - Culzoni, 2016

MOISSET DE ESPANESLUIS, ¿Tiene plazo de Caducidad la inscripción que da noticia de la realización de la subasta? Lexisnexis Cordoba 20073217.

MOISSET DE ESPANÉS Luis y FUSTER Gabriel Aníbal. "La Comunicación De Subasta". Revista Abeledo Perrot Córdoba, No 1 (enero 2009).

MOISSET DE ESPANÉS Luis y FUSTER Gabriel Aníbal. "La situación jurídica registrable del adquirente en subasta de un bien inmueble". DJ15/04/2009, 931. Cita Online: AR/DOC/1399/2009.

PALACIO, Lino Enrique. Derecho Procesal Civil, Buenos Aires, Abeledo-Perrot, 1969, t. VII.

VENTURA, Gabriel B. Tracto abreviado registral — Editorial Hammurabi — Buenos Aires, 2005

VENTURA, Gabriel B.; "La comunicación de subasta y el tercero registral", en www.acaderc.org.ar (disponible el día 01/08/2017), AP 003/70024558-1.

\section{LEGISLACION}

Código Civil y Comercial, Ley 26944

Ley Provincial 5771. B.O. 12.11.74

Ley Provincial 7191 B.O. 19.11.84

Ley Nacional 17801 B.O. 28.06.68

\section{JURISPRUDENCIA}

Cámara Civil y Comercial de $4^{\circ}$ Nominación, 25 de febrero de 2008, en autos: "Sahade Silvana Andrea c/ Milotich Hector y otros - Declarativo .- Tercería de Dominio - Dominio de Tarif Ramón Amin - Yaz de Azize" 
Tribunal Constitucional de España, Sala $1^{\circ}$, Sent. No 49, 30/03/2004. Recurso de amparo 4791-2001. Promovido por Nationale Nederlanden Vida Compañía de Seguros y Reaseguros, S.A.E., frente a un Auto de la Audiencia Provincial de Murcia en ejecución de Sentencia en causa por delitos de estafa y falsedad.

Cámara Civil y Comercial Mar del Plata, Sala 2, 04/02/2003, "Longo, Walter M. s./ Tercería de Dominio en autos Collia v. Fucci s./ Ejecución de Alquileres".

Cámara Quinta de Apelaciones en lo Civil y Comercial de la Provincia de Córdoba en autos "Repartidores de Kerosene de Y.P.F. de C.B.A. S.R.L. hoy Muñoz, Luis Alberto c. Frutacor S.A. s/ ordinario - cumplimiento / resolución de contrato".Publicado en:LLC2015 (abril), 336. Cita Online:AR/JUR/68871/2014 